\title{
Scale Development and an Educational Program to Reduce the Stigma of Schizophrenia Among Community Pharmacists: Study Protocol for a Randomized Controlled Trial
}

\section{Tomoo Fujii}

Meijo University Faculty of Pharmacy Graduate School of Pharmacy: Meijo Daigaku Yakugakubu Daigakuin Yakugaku Kenkyuka

\section{Manako Hanya}

Meijo University Faculty of Pharmacy Graduate School of Pharmacy: Meijo Daigaku Yakugakubu Daigakuin Yakugaku Kenkyuka

\section{Kenta Murotani}

Kurume University School of Medicine: Kurume Daigaku Igakubu Daigakuin Igaku Kenkyuka

Hiroyuki Kamei ( $\sim$ hkamei@meijo-u.ac.jp)

Meijo Daigaku Yakugakubu Yakugaku Kenkyuka https://orcid.org/0000-0003-3778-2352

\section{Research article}

Keywords: Pharmacist, Attitude, Contact-based educational programs, Stigma scale, Schizophrenia

Posted Date: November 19th, 2020

DOI: https://doi.org/10.21203/rs.3.rs-108763/v1

License: (c) (i) This work is licensed under a Creative Commons Attribution 4.0 International License. Read Full License

Version of Record: A version of this preprint was published at BMC Psychiatry on April 26th, 2021. See the published version at https://doi.org/10.1186/s12888-021-03208-z. 


\section{Abstract}

\section{Background}

Stigma associated with mental disorders is rooted among many pharmacists, and represents a major barrier to patient support in community-based psychiatry. In the current study, we firstly developed an assessment scale that is specifically designed to assess the level of stigma that pharmacists may have toward patients with schizophrenia, and then examined the effects of reducing stigma with an educational program that focuses on communication with schizophrenic patients using a newly developed Stigma Scale towards Schizophrenia for Community Pharmacists (SSCP).

Methods

SSCP was developed by exploratory factor analysis with promax rotation based on responses from 822 randomly selected community pharmacists. Furthermore, a randomized controlled trial was conducted for 115 community pharmacists to clarify the effects of reducing the stigma of schizophrenia using an educational program for them with a focus on communication with patients with schizophrenia. Participants were individually allocated to two groups: a lecture group (56; only attending a lecture on schizophrenia) or communication group (59; communicating with patients and attending the lecture). The stigma assessment using SSCP was conducted immediately before and after the educational intervention.

Results

A total of 4 factors and 27 items were extracted from the exploratory factor analysis as SSCP.

Cronbach's a of SSCP was 0.89; specifically, Cronbach's a for social distance at work (factor I), recognition of patients with schizophrenia (factor II), self-disclosure (factor III), and social distance in daily life (factor IV) were $0.88,0.76,0.62$, and 0.62 , respectively. Educational program-related changes of the median (interquartile range) total SSCP score from baseline were -9.0 (-16.0 - -5.0) in the communication group and -3.0 $(-7.0-1.0)$ in the lecture group, reflecting a significant reduction of stigma levels in the communication group. On examining the SSCP subscales, scores for factor I and factor II significantly improved. The educational program was more effective for pharmacists aged 20-39 years or with negligible experience of communicating with schizophrenic patients at work and/or in private life.

Conclusions

SSCP and the educational program for community pharmacists that focuses on communication with patients were useful for assessing and reducing, respectively, the stigma attached by these pharmacists to schizophrenia.

CONSORT extension for abstract

Not applicable

Trial registration

Not applicable

\section{Background}

The number of patients with mental disorders in Japan exceeded 3.9 million in 2014 and is steadily increasing [1]. Patients with schizophrenia account for nearly $50 \%$ of all long-term hospitalized patients ( $₫ 1$ year), and concerns have been expressed over their prolonged hospitalization [1]. The Ministry of Health, Labor and Welfare clarified its vision to promote a shift in mental healthcare from inpatient treatment to community life support in 2004 [2]. Therefore, pharmacists are 
increasingly expected to provide appropriate medical information and increase the quality of psychiatric services for mentally ill patients. However, a negative stereotype or stigma of mental disorders is rooted among many pharmacists [3, 4] and other healthcare professionals [5, 6] and represents a major barrier to patient support in community-based psychiatry. The stigma attached to mental disorders, specifically schizophrenia, is stronger in Japan than in other countries [7].

Community pharmacists play an important role in the care of patients with schizophrenia who require pharmacological treatments because they provide guidance on the effects and side effects of medication as well as support for continued adherence to medication [8]. However, stigma among pharmacists towards patients with schizophrenia may interfere with adherence and worsen symptoms if patients discontinue their medication [3, 9]. In our previous internet survey on stigmatic attitudes towards the mentally ill, involving 870 physicians, nurses, pharmacists, and general citizens in Japan, the stigmarelated scores of pharmacists were similar to those of physicians and nurses, and they had relatively positive attitudes towards the mentally ill [10]. On the other hand, in comparisons of pharmacists and general citizens, the recognition of mental illness was more positive in the former, but the social distance from these patients was similar between these groups, revealing the need to reduce this distance and decrease stigma among pharmacists [10]. The findings of this survey also suggested the effectiveness of appropriate communication with patients through working/training in psychiatric facilities to reduce social distance from patients with mental disorders $[5,10]$. In order to decrease the stigma of schizophrenia, psychological distance needs to be reduced and more positive attitudes have to be promoted towards these patients. Therefore, combining educational interventions based on knowledge of schizophrenia and appropriate communication with patients, rather than awareness-enhancing approaches, such as lectures alone, is considered to be more effective [11, 12].

Educational programs for pharmacists, with a focus on communicating with patients, may be important for reducing stigma. However, the effectiveness of contact-based educational programs for pharmacists to reduce the stigma of schizophrenia has not yet been demonstrated.

We previously employed stigma scales to measure general attitudes towards mental disorders and social distance manifested as avoidance responses to the mentally ill in society $[13,14]$. To confirm the effectiveness of educational programs for pharmacists, stigma scales that accurately simulate actual settings, in which pharmacists manage patients with schizophrenia, are essential.

Therefore, a scale to assess the stigma of schizophrenia among pharmacists was developed in the present study and its reliability was verified. A randomized controlled trial was then conducted to confirm the effectiveness of the pharmacist educational program with a focus on communication with patients to reduce the stigma of schizophrenia.

\section{Methods}

The present study was approved by the Meijo University Research Ethics Board to ensure privacy, confidentiality, and anonymity (H30-3). It was conducted according to the principles expressed in the Declaration of Helsinki.

\section{Development of a scale to assess the stigma of schizophrenia among community pharmacists}

To develop a scale to assess the stigma of schizophrenia among community pharmacists, items related to the constructs of stigma as a barrier for pharmacists to provide professional support for patients with schizophrenia were extracted from existing scales [5, 15-18]. A pool of items was created with these items and those newly developed upon deliberations among 3 pharmacists (1 university professor conducting research on psychiatry, 1 communication specialist, and 1 researcher). There were 67 items, representing 3 constructs; 1 ) recognition of patients with schizophrenia, 2) social distance, and 3) self-disclosure/help-seeking behavior. The appropriateness of the 67 items in terms of content and 
expression was then examined with 12 pharmacists, including 2 of the above-mentioned pharmacists and 3 pharmacists specializing in psychiatry, and a 33-item scale was created.

The assessment tool was distributed with a survey on personal background information to 1,500 pharmacies in Aichi Prefecture between December 1, 2018, and January 31, 2019. These pharmacies were randomly selected. A 5-point scale was used in the assessment tool as follows: 1: strongly agree, 2: agree, 3: neither agree nor disagree, 2: disagree, 1: strongly disagree. Negative responses were given 5 points, and positive responses 1 point. Correlations between each item and the total score (item total correlation) were confirmed from the scale proposals collected. Based on the answers provided, an exploratory factor analysis was performed using the principal axis factoring method with a promax rotation to further examine the factors constituting the assessment tool. The 33-item scale created by 12 pharmacists described above was extracted into a 27 -item scale by the factor analysis.

Cronbach's a confidence coefficient was calculated for each item and factor of the assessment tool to assess the level of internal consistency. The correlation between the total score and social desirability scale $[19,20]$ was confirmed from the 27 -item scale. The test-retest reliability of the 27 -item scale was verified by conducting a retest for those who consented among the sub-sample of community pharmacists eight to twelve weeks after the completion of the survey, and the intraclass correlation comparing the total scores at the 2 points they completed was calculated.

Furthermore, to confirm criterion-related validity, the correlation between the total 27 -item scale score and total score from the following 2 conventional scales was used to assess the stigma of mental disorders: the Whatley Social Distance Scale (WSDS) [17] and Index of Attitudes toward the Mentally III (IATM) [15]. WSDS examines attitudes that prevent social participation by patients with mental disorders (social distance), and IATM measures the levels of negative recognition of these disorders. We used the 2 scales in our previous studies, involving pharmacy students [13], and an internet survey [10], conducted by physicians, nurses, pharmacists, and general citizens. The scale developed through these processes was named the Stigma Scale towards Schizophrenia for Community Pharmacists (SSCP), and was used in subsequent studies.

\section{Randomized controlled trial}

A randomized controlled trial was conducted to clarify the effects of reducing the stigma of schizophrenia using an educational program for community pharmacists with a focus on communication with patients with schizophrenia.

\section{Participants and study design}

An outline of the study design is shown in Figure 1. Community pharmacies in Aichi Prefecture in Japan were randomly selected to receive a document to recruit participants by e-mail or post, and consent was obtained from 120 pharmacists belonging to these pharmacies. They participated in the educational program twice, on July 28 and November 10, 2019, and were divided into 2 groups of 60, adopting the stratified block randomization method using a computer-generated randomization list with a block size of four: a lecture group (only attending a lecture on schizophrenia) and communication group (communicating with patients with schizophrenia and attending the lecture). Randomization was stratified by (1) sex (female versus male), (2) age (<30 years versus $>30$ years), (3) experience of communicating with patients with mental disorders (whether participants have or do not have this experience). Following the exclusion of 4 participants in the lecture group and 1 in the communication group, who withdrew, the final numbers in each group were 56 and 59, respectively (a total of 115 participants). Approximately $50 \%$ of each group participated in each session. After the lecture, the group to which each participant belonged was disclosed.

\section{Outline of the educational program}

All 115 participants attended a 60-minute lecture on schizophrenia given by a psychiatrist. The contents of the lecture were the epidemiology, symptoms, diagnosis, treatment methods based on the latest evidence, treatment effects, main side effects, and prognosis of schizophrenia.

Page $4 / 19$ 
After the lecture, 59 communication members formed groups of 4 or 5 to perform the following activities in a single room: a lecture staff introduction and breaking the ice (self-introduction in each group); a lecture on mental disorders and the associated stigma (prejudice and discrimination); group work 1: holding a group discussion on the management of patients with schizophrenia, and making a presentation with 1 member of each group (a total of 5 groups) as the presenter; group work 2: holding a group discussion and offering opinions on the points of an interview with patients with schizophrenia to clarify their experience; an interview with a patient with schizophrenia, who was allocated to the table of each group (a total of 6 patients), and introduced him/herself for 20 minutes using a self-introduction sheet previously filled out; interviews with 2 other patients (a total of 3 rotations); group work 3: holding a group discussion on points of learning by pharmacists from patient experiences, making a presentation with 1 member of each group (a total of 5 groups) as the presenter, followed by a lecture to summarize the opinions offered at the group presentations.

The 6 ( 4 males and 2 females) patients with schizophrenia who shared their experiences belonged to a patient group in Nagoya city. They had taken antipsychotics for 5 years or longer and were visiting psychiatric hospitals as outpatients. Their signed consent was previously obtained using a written document specifying the study objective.

After the consent process, they entered: 1) medical history, 2) difficulties associated with pharmacotherapy, 3) issues they may or may not consult about with community pharmacists, 4) cases in which they had perceived stigmatizing behaviors/attitudes (prejudice and discrimination), and 5) demands to be fulfilled by community pharmacists, in a selfintroduction sheet, and rehearsed self-introductions using this sheet.

\section{Stigma assessment}

The stigma of schizophrenia among community pharmacists was assessed using SSCP at 3 points: before the lecture (both groups: T1), immediately after the lecture (lecture group: T2), and immediately after communicating with patients (communication group: T3). SSCP consists of 27 statements to be evaluated on a 5-point scale: <Strongly agree>, <Agree>, $<$ Neutral>, <Disagree>, and <Strongly disagree>, which were scored as 1-5, respectively. Five items among 27 statements were reverse scored (i.e., \#11, 20, 24, 25, and 26). The total score ranged between 27 and 135. Scores that were higher than or equal to a median of 81 represented more favorable attitudes.

\section{Statistical analysis}

Statistical analyses were performed using IBM SPSS statistics ver. 22. The attributes of the 2 groups were compared using the Mann-Whitney $U$ test and chi-squared test. The Wilcoxon signed-rank test was used to compare between before and after the educational program. The effect size $r$ was calculated using the standardized test statistic $(Z)$ and sample size $(M)(r=Z / \sqrt{ } N)$. An effect size of 0.1 was considered to be small, 0.3 medium, and 0.5 or more a large effect. The significance of differences was set at two-tailed $p<0.05$ unless otherwise specified.

To identify fundamental factors from the 33-item scale, an exploratory factor analysis was performed using the principal axis factoring method with a promax rotation. The choice of the number of factors was based on the scree plot. Items with factor loadings lower than 0.4 were deemed meaningful and assigned to the given factor, with only the highest factor loading for each item being considered. Even if an item had a factor load of lower than 0.4 , the item was adopted if researchers found it necessary to explain the construct to which the item belongs. We labeled each factor based on what best characterized the group of items that loaded on a particular factor. The internal consistency of the SSCP and subscales was evaluated using Cronbach's a coefficient and construct validity for SSCP was examined using Spearman's correlation (rs).

\section{Results}

Testing of the 33 -item scale to assess reducing stigma 


\section{Response rate and respondent characteristics}

There were 822 responses (response rate: $54.8 \%$ ), and 806 were valid for analysis (Valid response rate: $53.7 \%$ ). The mean age of respondents was $42.3 \pm 12.1$ years. There were $490(60.8 \%)$ males and $316(39.2 \%)$ females. Their mean length of pharmacy experience was $15.6 \pm 10.4$ years.

\section{Item-total correlations}

An item-total correlation of 0.2 to 0.5 is considered to be the most appropriate [16]. None of the 33 statements showed an item-total correlation of lower than 0.2.

\section{Exploratory factor analysis}

Table 1 shows factorial patterns after the promax rotation, inter-factor correlations, Cronbach's a coefficient, and the median (inter-quartile range) for each item. Prior to the factor analysis, the mean score and standard deviation for each item were calculated to confirm the absence of a ceiling or floor effect. In the Kaiser-Meyer-Olkin measure of sampling adequacy, it is recommended that a range of 0-1 be allowed and values need to be higher than 0.6. The factor model showed a coefficient of 0.91 , confirming its sufficient sampling adequacy.

Significant results $(\chi 2 \otimes 6578.2, d f=351, p<0.001)$, confirming the appropriateness of this model, were also obtained from Bartlett's test for Sphericity. Following the examination of all 33 items through an exploratory factor analysis, 4 factors and 27 items were selected. The cumulative proportion of variance explained was $45.8 \%$. Six items with a factor loading lower than 0.4 were removed. The 6 items removed were as follows: "When patients with schizophrenia present with physical symptoms (e.g. nausea, back pain, headache), I might think that they are manifested because of mental issues", "I feel that there is nothing I can do for patients with schizophrenia in terms of their recovery", "I cannot understand the behavior of patients with schizophrenia that is caused by hallucinations and delusions", "I think I can actively identify specific problems that patients with schizophrenia may have", "I cannot be friends with a patient with schizophrenia", and "If I had schizophrenia and was not able to control the symptoms myself, I would consider myself a weak person".

However, items judged to be necessary for explaining the components were not excluded, even if factor loading was lower than 0.4. The 4 factors were named as follows: Factor l; social distance at work, Factor Il; recognition of patients with schizophrenia, Factor III; self-disclosure, and Factor IV; social distance in daily life. The median (inter-quartile range) of the total score was 70.0 (63.0-78.0) for the entire scale, 29.0 (25.0-34.0) for factor I, 19.0 (17.0-22.0) for factor II, 11.0 (10.012.0) for factor III, and 10.0 (9.0-12.0) for factor IV. These scores indicated a relatively positive response because they were lower than $50 \%$ of the total score.

\section{Testing of the 27-item scale to assess reducing stigma}

\section{Internal consistency}

Cronbach's $a$ was 0.89 for the entire scale, 0.88 for <Factor I: social distance at work>, 0.76 for <Factor II: recognition of patients with schizophrenia>, and 0.62 for <Factor III: self-disclosure> and <Factor IV: social distance in daily life>.

\section{Test-retest reliability}

Among the initial samples, a subset of 81 consented to the retest. The intra-class correlation between the total scores at the 2 points was $0.90(95 \% \mathrm{Cl} 0.84-0.93, p<0.001)$, exceeding 0.7 , and, thus, the value confirmed sufficient reliability.

\section{Social desirability bias}


No correlation was observed between the total SSCP score of 806 pharmacists and the total social desirability scale ( $r s=$ $-0.117, p \otimes 0.213)$.

\section{Criterion-related validity}

The correlation between the total SSCP score and total WSDS/IATM scores was calculated. Total score correlations between SSCP and WSDS or IATM were $0.58(p<0.001)$ and $-0.62(p<0.001)$, respectively.

\section{Randomized controlled trial to assess effects of contact-based educational programs on lectures alone.}

No significant differences were observed in participant backgrounds between the 2 groups (Table 2).

\section{Effects of the contact-based educational program on reducing stigma}

In the communication and lecture groups, the total SSCP score and Factor I, II, and III scores after the educational program were significantly better than the baseline score (Table 3). Educational program-related changes in the median (interquartile range) total SSCP score were $-9.0(-16.0--5.0)$ in the communication group and $-3.0(-7.0-1.0)$ in the lecture group (improvement rate, $15.5 \%$ and $5.2 \%$, respectively; $p<0.001$ ) (Table 3 ).

The improvement rates for each factor in the communication and lecture groups were as follows: Factor I: 18.3 and $7.1 \%$, II: 23.0 and 4.5\%, III: 5.0 and 6.7\%, and IV: 1.0 and $0 \%$, respectively, revealing marked improvements in scores for Factors I and II ( $p=0.001$ and $p<0.001$, respectively). The effect sizes associated with the contact-based educational session were as follows: entire SSCP: 0.41 , Factor I: 0.32 and II: 0.49 , respectively, revealing a moderate difference among both groups.

\section{Effects of demographic characteristics on differences in stigma between two groups}

Table 4 shows the effects of demographic characteristics on differences in stigma between the 2 groups. Among participants in their 40s and older or who had experience of schizophrenia via family members or close friends or provide medication counseling for a few patients with schizophrenia each week, no additional effect of the contact-based educational intervention on the lecture was observed. However, in all subgroups other than that described above, participants in the communication group showed a significantly greater change than those in the lecture group.

\section{Discussion}

The role of community pharmacists in Japan is becoming an important challenge because the number of outpatients with schizophrenia is expected to steadily increase in the future. However, the stigma of community pharmacists towards schizophrenia is a major barrier to medication support for these patients, and also keeps pharmacists themselves from making the most of their professional skills. To the best of our knowledge, the present study is the first to develop a scale to specifically assess the stigma of schizophrenia among community pharmacists in Japan. By achieving Cronbach's $a$ of 0.7 or higher for the entire scale, SSCP had sufficient internal consistency and appears to be a reliable and valid scale for assessing the stigma of schizophrenia among community pharmacists. Furthermore, a randomized controlled trial design was adopted in the present study and confirmed the effects of contact-based educational interventions using SSCP to reduce the stigma of schizophrenia among community pharmacists. A previous study reported that the recurrence rate was approximately 5 -fold higher among patients with schizophrenia who discontinued their medication than among adherent patients [21]. The stigma of schizophrenia among pharmacists negatively affects medication-related behaviors by patients, which may lead to worse symptoms due to medication withdrawal $[22,23]$.

Many community pharmacists at work in Japan keep their social distance from patients with mental disorders [10], and concerns have been expressed over stigmatization by pharmacists, which increases the difficulties associated with appropriately managing these patients. 
In pharmacotherapy for schizophrenia, for which poor medication adherence is regarded as problematic [23, 24], community pharmacists need to continuously provide medication support, including confirmation of the therapeutic and adverse effects of drugs, which helps patients to continue their medication and improve their quality of life in a responsible manner. The total SSCP and 4 factor scores of 115 pharmacists who participated in the educational program as part of the present study were lower than the midpoints. Thus, participants were individuals with relatively positive attitudes towards patients with schizophrenia. Moreover, their values were similar to those in our previous study to develop SSCP, involving 822 community pharmacists.

In comparisons of the 2 groups (lecture and communication) based on the results of the randomized controlled trial, SSCP scores improved more in the communication group, supporting the usefulness of the educational program combining educational interventions based on knowledge of schizophrenia and communication with patients to reduce the stigma of this disorder among community pharmacists. The lecture on schizophrenia itself also effectively reduced this stigma; however, the effect was enhanced by adding communication with patients to the lecture. The effectiveness of an educational intervention to reduce the stigma of mental disorders has already been confirmed in meta-analyses performed in other countries [11]. Social contact or contact-based interventions have been identified as the most effective strategy [12]. Griffiths et al. previously reported that the effects of social contact to reduce stigma is enhanced by combining it with knowledge-based education [11], and these findings support the present results. Pettigrew and Tropp reported curricula complementing knowledge-based elements of education with social contact to effectively reduce stigma by decreasing anxiety and promoting empathy [25].

The present study adopted an unconventional program to provide interventions for pharmacists, with a focus on communication with patients. In this program, pharmacists initially held group discussions to clarify the difficulties associated with managing patients with schizophrenia in daily services, and then classified their questions about these patients to directly ask them to actual patients for confirmation during a communication session for each group. Some of the questions from pharmacists, such as "How would you describe the stigmatic attitudes, statements, and behaviors any pharmacists have ever shown towards you?", "How did you feel when you actually perceived any stigmatization by pharmacists?", and "What do you expect from pharmacist?", highlighted the issue of stigma, and patients freely answered these questions. At the end of the program, the communication group discussed approaches to be adopted by pharmacists in the future based on their experience of communicating with patients.

This educational intervention content was originally provided in this program, and its usefulness was confirmed by the stronger stigma-reducing effect achieved in the communication group than in the lecture group. In any case, there is currently no other educational program that specifically addresses the stigma of schizophrenia among community pharmacists in Japan or other countries.

Among the SSCP subscale scores, <Factor II: recognition of patients with schizophrenia> improved the most, possibly contributing to the improvements observed in scores for <Factor l: Social distance at work $>$, which prevents pharmacists from making the most of their professional skills.

In our previous study, the feasibility of reducing the social distance of community pharmacists from patients with schizophrenia by resolving their misunderstanding of these patients as dangerous was also suggested [26]. Furthermore, the establishment of an equal relationship between healthcare professionals and patients through contact-based education has been reported to contribute to reducing this social distance [27]. Community pharmacists communicate with patients with schizophrenia in the context of a healthcare professional-patient relationship in regular pharmacy services, whereas they do so in the context of closer, person-to-person relationships in contact-based education.

Regarding the management of patients with mental disorders, community pharmacists do not perceive any difficulty in providing explanations of prescriptions (such as the drug name, dosage, and dose) for these patients or explaining and confirming drugs representing their medication status; however, they encounter greater difficulties in confirming the living 
conditions, status/views of work (school activity), and daily life activities of these patients, such as monitoring their subjective symptoms and side effects and providing coping support $[3,28]$. Pharmacists who participated in the communication session during the educational program previously held group discussions and reflected on their previous experiences of the management of patients with schizophrenia to classify their questions to directly ask these patients and be resolved. By freely exchanging opinions beyond the boundary between patients and healthcare professionals during the communication session after this work, pharmacists may have been able to clarify their questions about patients with schizophrenia, which may be more difficult to resolve in regular pharmacy service, and this may have consequently resolved their misunderstanding of these patients and reduced their social distance at work. On the other hand, no significant differences were observed in the scores for 2 SSCP factors: <Factor III: self-disclosure> and <Factor IV: social distance in daily life $>$, between the lecture and communication groups. Additionally, no significant improvements were observed in the scores for <Factor IV: social distance in daily life> after the educational program. The reason for this currently remains unclear; however, it may be necessary to reconsider the number of SSCP factors and their contents. Regarding the relationship between pharmacies, backgrounds, and SSCP scores, there was no additional effect of communication with patients in pharmacists aged 40 or older and those who frequently communicated with patients with schizophrenia at work and/or in their private life, suggesting that the educational program is more effective for pharmacists aged 20-39 years or with negligible experience of this form of communication. Since only limited empirical data on the influence of personal characteristics (such as sex and age) on anti-stigma education are available, further research is needed.

The present study has a number of limitations. The stigma-reducing effect was only evaluated immediately after the educational intervention. The duration of this effect of contact-based educational interventions varies among studies, from immediately [29] to 12 months [30] after the intervention. Therefore, future studies are needed to examine the duration of the effects of contact-based educational interventions for community pharmacists in Japan as well as the effectiveness of repeated interventions. Moreover, further studies are required to clarify actual changes in the behavior of and daily services provided by pharmacists after participating in an educational program.

\section{Conclusion}

The present results suggested the usefulness of our original scale of SSCP and educational program for community pharmacists with a focus on communication with patients to assess and reduce, respectively, the stigma attached to schizophrenia by these pharmacists, among whom stigmatization is more serious than in other areas of mental health services.

\section{Abbreviations}

SSCP: Stigma Scale towards Schizophrenia for Community Pharmacists

WSDS: the Whatley Social Distance Scale

IATM: Index of Attitudes toward the Mentally III

\section{Declarations}

\section{Ethics approval and consent to participate}

The present study was approved by the Meijo University Research Ethics Board to ensure privacy, confidentiality, and anonymity (H30-3). It was conducted according to the principles expressed in the Declaration of Helsinki. All participants were informed about the study, and all provided written informed consent. 


\section{Consent for publication}

Not applicable

Availability of data and materials

The datasets used and/or analyzed during the current study are available from the corresponding author on reasonable request.

\section{Competing interests}

The authors declare that they have no competing interests.

\section{Funding}

This study was supported by JSPS KAKENHI, Grant Number JP19K07178. Funder had no involvement in the study design; in the collection, analysis and interpretation of data; in the writing of the report; nor in the decision to submit the article for publication.

\section{Authors' contributions}

$\mathrm{TF}, \mathrm{MH}, \mathrm{KM}$, and $\mathrm{HK}$ were responsible for the study concept and design. TF were responsible for collection of data from participants. TF and KM were responsible for statistical analysis. TF and HK were responsible for drafting the manuscript. All authors were responsible for critical revision of the manuscript and have accepted the final version.

\section{Acknowledgements}

We are grateful to Dr. Kazuto Oya for his lecture on schizophrenia and to each member of the patient group in Nagoya for their support with the communication session. We would also like to thank Dr. Masakazu Hatano, Dr. Ippei Takeuchi, Mr. Shogo Hotta, Mr. Genta Hazithu, Ms. Kaori Tozawa, Mr. Takashi Sakakibara, Ms. Sayuri Ono, and Ms. Mihiro Taniguchi for their support as facilitators during the communication session.

\section{References}

1. Number of Patients with Mental Illness. https://www.mhlw.go.jp/kokoro/speciality/data.html. Accessed 10 September 2020.

2. Visions to Improve Mental Healthcare, Medical, and Welfare Services. https://www.mhlw.go.jp/kokoro/nation/vision.html. Accessed 10 September 2020.

3. Phokeo V, Sproule B, Raman-Wilms L: Community pharmacists' attitudes toward and professional interactions with users of psychiatric medication. Psychiatric services (Washington, DC) 2004, 55(12):1434-1436.

4. Scheerder G, De Coster I, Van Audenhove C: Pharmacists' role in depression care: a survey of attitudes, current practices, and barriers. Psychiatric services (Washington, DC) 2008, 59(10):1155-1160.

5. Hori H, Richards M, Kawamoto Y, Kunugi H: Attitudes toward schizophrenia in the general population, psychiatric staff, physicians, and psychiatrists: a web-based survey in Japan. Psychiatry Res 2011, 186(2-3):183-189.

6. Nordt C, Rössler W, Lauber C: Attitudes of mental health professionals toward people with schizophrenia and major depression. Schizophrenia bulletin 2006, 32(4):709-714.

7. Ando S, Yamaguchi S, Aoki Y, Thornicroft G: Review of mental-health-related stigma in Japan. Psychiatry and clinical neurosciences 2013, 67(7):471-482. 
8. Rubio-Valera M, Chen TF, O'Reilly CL: New roles for pharmacists in community mental health care: a narrative review. Int J Environ Res Public Health 2014, 11(10):10967-10990.

9. O'Reilly CL, Bell JS, Kelly PJ, Chen TF: Exploring the relationship between mental health stigma, knowledge and provision of pharmacy services for consumers with schizophrenia. Res Social Adm Pharm 2015, 11(3):e101-109.

10. Fujii T, Hanya M, Kishi M, Kondo Y, Cates ME, Kamei H: An internet-based survey in Japan concerning social distance and stigmatization toward the mentally ill among doctors, nurses, pharmacists, and the general public. Asian journal of psychiatry 2018, 36:1-7.

11. Griffiths KM, Carron-Arthur B, Parsons A, Reid R: Effectiveness of programs for reducing the stigma associated with mental disorders. A meta-analysis of randomized controlled trials. World psychiatry : official journal of the World Psychiatric Association (WPA) 2014, 13(2):161-175.

12. Thornicroft G, Mehta N, Clement S, Evans-Lacko S, Doherty M, Rose D, Koschorke M, Shidhaye R, O'Reilly C, Henderson C: Evidence for effective interventions to reduce mental-health-related stigma and discrimination. Lancet (London, England) 2016, 387(10023):1123-1132.

13. Ono S, Hanya M, Tanaka $\mathrm{H}$, Cates ME, Kamei $\mathrm{H}$ : Changes in attitudes of Japanese pharmacy students towards mental illness during the didactic portion of the curriculum. Pharmacy Education 2013, 13:145-150.

14. Cates ME, Bright JT, Kamei H, Woolley TW: Attitudes of Japanese Pharmacy Students Toward Mental Illness. Pharmacy Education 2011, 11:132-135.

15. Hiday VA: Are lawyers enemies of psychiatrists? A survey of civil commitment counsel and judges. The American journal of psychiatry 1983, 140(3):323-326.

16. Kassam A, Papish A, Modgill G, Patten S: The development and psychometric properties of a new scale to measure mental illness related stigma by health care providers: the Opening Minds Scale for Health Care Providers (OMS-HC). BMC psychiatry 2012, 12:62.

17. Whatley C: Social attitudes toward discharged mental patients. Social Problems 1959, 6(4):313-320.

18. Uçok A, Soygür H, Atakli C, Kuşcu K, Sartorius N, Duman ZC, Polat A, Erkoç S: The impact of antistigma education on the attitudes of general practitioners regarding schizophrenia. Psychiatry and clinical neurosciences 2006, 60(4):439443.

19. Makita K: Development and reliability of the Japanese-language version of Social Distance Scale. Jpn Bull Soc Psychiat 2006, 14:231-241.

20. Hathaway SR, McKinley JC: An authorized translation and adaptation of the Minnesota Multiphasic Personality Inventory. New York: the Psychological Corporation; 1966.

21. Hegarty JD, Baldessarini RJ, Tohen M, Waternaux C, Oepen G: One hundred years of schizophrenia: a meta-analysis of the outcome literature. The American journal of psychiatry 1994, 151(10):1409-1416.

22. Black E, Murphy AL, Gardner DM: Community pharmacist services for people with mental illnesses: preferences, satisfaction, and stigma. Psychiatric services (Washington, DC) 2009, 60(8):1123-1127.

23. Higashi K, Medic G, Littlewood KJ, Diez T, Granström O, De Hert M: Medication adherence in schizophrenia: factors influencing adherence and consequences of nonadherence, a systematic literature review. Ther Adv Psychopharmacol 2013, 3(4):200-218.

24. Phan SV: Medication adherence in patients with schizophrenia. Int J Psychiatry Med 2016, 51(2):211-219.

25. Pettigrew TF, Tropp LR: How does intergroup contact reduce prejudice? Meta-analytic tests of three mediators. European Journal of Social Psychology 2008, 38(6):922-934.

26. Fujii T, Hanya M, Yoshimi A, Noda Y, Kamei H: Usefulness of a Workshop Focusing on Communication with Patients to Reduce the Stigma of Schizophrenia among Community Pharmacy Pharmacists. Journal of Japanese Psychopharmaceutical Society 2020, 3(2):2-10. 
27. Bell JS, Johns R, Rose G, Chen TF: A comparative study of consumer participation in mental health pharmacy education. The Annals of pharmacotherapy 2006, 40(10):1759-1765.

28. Kishimoto K, Toshiya M, Ohiwa S, Yamaura K, Fukushima N: Factors Improving Pharmacists' Services for Patients with Depression. Japanese Journal of Pharmaceutical Health Care and Sciences 2016, 42(12):795-808.

29. Papish A, Kassam A, Modgill G, Vaz G, Zanussi L, Patten S: Reducing the stigma of mental illness in undergraduate medical education: a randomized controlled trial. BMC medical education 2013, 13:141.

30. O'Reilly CL, Bell JS, Chen TF: Consumer-led mental health education for pharmacy students. Am J Pharm Educ 2010, 74(9):167.

\section{Tables}

Table 1. Factorial patterns after the promax rotation for community pharmacists 


\section{7 items $a=0.89$}

Extraction factor

I II III IV Median (interquartile range)

\section{Factor I: Social distance at work, $a=0.88$}

1. If possible, I would rather avoid administering and advising about medication for patients with schizophrenia. $\begin{array}{lllll}0.89 & -0.11 & -0.03 & 0.03 & 2.0\end{array}$

$(2.0-$

3.0)

2. If possible, I would rather avoid consultations with patients with schizophrenia as much as possible.

$\begin{array}{lllll}\mathbf{0 . 7 8} & -0.08 & 0.04 & -0.03 & 2.0 \\ & & & & (2.0- \\ & & & 3.0)\end{array}$

3. If possible, I would rather avoid home visits for patients with schizophrenia.

$\begin{array}{lllll}0.73 & -0.10 & 0.04 & 0.04 & 3.0\end{array}$

(2.0-

4.0)

4. I feel that it is too much work to deal with patients with schizophrenia.

$\mathbf{0 . 7 2} \quad 0.09 \quad-0.11 \quad-0.02 \quad 3.0$

$(2.0-$

3.0)

5. I would rather be involved in care for patients with physical illnesses than those with schizophrenia.

$\begin{array}{lllll}0.63 & 0.08 & -0.11 & -0.01 & 3.0 \\ & & & & (2.0\end{array}$

$(2.0-$

3.0)

6. I am afraid of administering and advising about medication for patients with schizophrenia.

$\begin{array}{lllll}0.58 & 0.01 & 0.02 & 0.05 & 2.0 \\ & & & & (2.0- \\ & & & 3.0)\end{array}$

7. If a patient hands me a prescription that includes medications for schizophrenia, I would try to avoid discussing his/her illness as much as possible.

$\begin{array}{lllll}0.55 & 0.03 & 0.18 & -0.17 & 3.0 \\ & & & & (2.0- \\ & & & 4.0)\end{array}$

8. I find it difficult to deal with patients with schizophrenia, particularly during busy hours.

$\begin{array}{lllll}0.55 & 0.18 & 0.03 & -0.18 & 3.0 \\ & & & (2.0- \\ & & & \\ & & & \end{array}$

4.0)

9. Despite my principles as a health care provider, I react negatively to patients with schizophrenia.

$\begin{array}{lllll}0.53 & 0.19 & -0.03 & 0.04 & 2.0 \\ & & & & (2.0- \\ & & & & 3.0)\end{array}$

10. I find it difficult to communicate with patients with schizophrenia.

$\begin{array}{lllll}0.52 & 0.08 & 0.07 & -0.06 & 3.0 \\ & & & & (2.0- \\ & & & 4.0)\end{array}$

11. I am not worried about dealing with situations in which I receive prescriptions or medication records for schizophrenia medications from $\mathbf{0 . 4 7} \quad-0.17 \quad-0.02 \quad 0.18$ 2.0 patients. (R) 


\section{Factor II: Recognition of patients with schizophrenia, $a=0.76$}

12. I think that schizophrenia affects the daily lives of patients.

$-0.05$

$\mathbf{0 . 6 4} \quad 0.02 \quad-0.00$

2.0

(2.0-

3.0)

13. I do not think that patients can recover from schizophrenia.

$-0.01$

0.58

$-0.01 \quad 0.08$

2.0

(2.0-

3.0)

14. I think that patients with schizophrenia are not capable of understanding their own illness.

$\begin{array}{lllll}0.02 & 0.55 & 0.04 & -0.07 & 2.0\end{array}$

(2.0-

3.0)

15. I think that patients with schizophrenia are always suffering from symptoms that include hallucination and delusion.

$-0.08$

$\mathbf{0 . 5 4} \quad-0.03 \quad-0.00$

2.0

16. I think that patients with schizophrenia are not capable of

0.00

0.53

$0.04 \quad 0.05$

2.0

understanding and adhering to the suggested treatment regimen.

$(2.0-$

3.0)

17. I think that more than $50 \%$ of patients with schizophrenia are not

working hard enough to improve their own conditions.

0.09

0.4

$\begin{array}{lll}-0.08 & -0.05 & 2.0\end{array}$

2.0

3.0)

18. I think that patients with schizophrenia have difficulties reintegrating $\begin{array}{lllll}0.04 & \mathbf{0 . 4 3} & 0.04 & 0.11 & 3.0\end{array}$ into society.

$\begin{array}{lllll}0.04 & 0.43 & 0.04 & 0.11 & 3.0\end{array}$

$(2.0-$

3.0)

19. I think that patients with schizophrenia are dangerous.

$\begin{array}{llll}0.19 & 0.35 & -0.01 & 0.11\end{array}$

3.0

\section{Factor III: Self-disclosure, $a=0.62$}

20. Unlike other diseases, if I had schizophrenia, I would be able to tell my friends about it. $(R)$

$\begin{array}{llll}0.06 & -0.14 & \mathbf{0 . 5 8} & 0.11\end{array}$

21. Unlike other diseases, if I had schizophrenia, I would not be easily able to tell my family about it.

$\begin{array}{lllll}0.08 & 0.03 & 0.57 & 0.05 & 2.0\end{array}$

22. Unlike other diseases, I would not be able to tell my colleagues that I was being treated for schizophrenia.

$\begin{array}{lllll}0.07 & -0.02 & 0.57 & -0.03 & 4.0\end{array}$

23. Unlike other diseases, if I had schizophrenia, I would hesitate to seek $\begin{array}{lllll}-0.03 & 0.17 & \mathbf{0 . 4 2} & -0.11 & 2.0\end{array}$ help from health professionals.

\section{Factor IV: Social distance in daily life, $\alpha=0.62$}

24. If a colleague of mine told me that he/she has schizophrenia that has been well-managed by medications, I would still be able to work with him/her without any issues. (R)

$\begin{array}{lllll}-0.04 & -0.00 & -0.00 & 0.66 & 2.0 \\ & & & & (2.0- \\ & & & 3.0)\end{array}$

25. If a candidate has the most appropriate skills for the job, employers $\begin{array}{llllll}-0.14 & 0.06 & 0.03 & 0.55 & 2.0\end{array}$ should hire a patient whose symptoms of schizophrenia are wellmanaged by medications. (R)

26. I would not mind if a patient with schizophrenia lived next door. (R)

$0.22 \quad 0.01-0.06$

0.40

3.0

(2.0-

4.0)

27. I would not want my children to work with a patient with schizophrenia even if his/her symptoms are well-managed by

0.19

0.13

0.10

0.36

2.0 


\begin{tabular}{|llllll|}
\hline Factor correlation & 1.00 & .59 & .42 & .38 \\
\hline & .59 & 1.00 & .37 & .42 \\
\hline & .42 & .37 & 1.00 & .29 \\
\hline
\end{tabular}

$n=806$. (R): reverse scored. The values for Factor I to IV represent factor loading.

Table 2. Baseline characteristics of participants in a randomized controlled study 


\begin{tabular}{|c|c|c|c|}
\hline \multirow[t]{2}{*}{ Characteristics } & \multirow{2}{*}{$\begin{array}{l}\text { Lecture group } \\
n=56\end{array}$} & \multicolumn{2}{|l|}{$\begin{array}{l}\text { Communication } \\
\text { group }\end{array}$} \\
\hline & & $n=59$ & $p$ \\
\hline Gender, \%female & 41.1 & 42.4 & 0.89 \\
\hline Age, years: mean \pm S.D. & $36.8 \pm 8.9$ & $37.7 \pm 10.0$ & 0.82 \\
\hline \multicolumn{4}{|l|}{ Age group: \% } \\
\hline $20-29$ & 26.8 & 28.8 & \multirow[t]{4}{*}{0.93} \\
\hline $30-39$ & 37.5 & 32.2 & \\
\hline $40-49$ & 23.2 & 23.7 & \\
\hline $50<$ & 12.5 & 15.2 & \\
\hline Pharmacist, years: mean \pm S.D. & $10.3 \pm 6.9$ & $11.9 \pm 9.3$ & 0.70 \\
\hline Psychiatric work experience, \%positive & 30.4 & 25.4 & 0.56 \\
\hline $\begin{array}{l}\text { Experience of mental illness via a family member or close friend, } \\
\text { \%positive }\end{array}$ & 32.1 & 32.2 & 0.99 \\
\hline $\begin{array}{l}\text { Experience of schizophrenia via a family member or close friend, } \\
\text { \%positive }\end{array}$ & 12.5 & 10.2 & 0.69 \\
\hline \multicolumn{4}{|l|}{$\begin{array}{l}\text { Frequency of medication counseling for schizophrenia patients, } \\
\text { \%positive }\end{array}$} \\
\hline Almost every day & 0 & 1.7 & \multirow[t]{5}{*}{0.37} \\
\hline A few patients a week & 12.5 & 11.9 & \\
\hline A few patients a month & 42.9 & 39.0 & \\
\hline A few patients a year & 21.4 & 32.2 & \\
\hline Nothing & 23.2 & 15.3 & \\
\hline SSCP, median (inter-quartile range) & $\begin{array}{l}74.0(67.0- \\
82.0)\end{array}$ & $71.0(66.0-80.0)$ & 0.276 \\
\hline Factor I, median (inter-quartile range) & $\begin{array}{l}32.0(29.0- \\
37.0)\end{array}$ & $31.0(26.0-36.0)$ & 0.242 \\
\hline Factor II, median (inter-quartile range) & $\begin{array}{l}20.0(18.0- \\
22.0)\end{array}$ & $20.0(18.0-22.0)$ & 0.840 \\
\hline Factor III, median (inter-quartile range) & $\begin{array}{l}12.0(9.0- \\
14.0)\end{array}$ & $11.0(9.0-13.0)$ & 0.336 \\
\hline Factor IV, median (inter-quartile range) & $\begin{array}{l}10.0(9.0- \\
11.8)\end{array}$ & $10.0(8.0-12.0)$ & 0.292 \\
\hline
\end{tabular}

Table 3. SSCP score before and after the intervention 


\begin{tabular}{|c|c|c|c|c|c|c|c|c|c|c|}
\hline & \multicolumn{4}{|c|}{ Lecture group } & \multicolumn{6}{|c|}{ Communication group } \\
\hline & \multicolumn{4}{|l|}{$n=56$} & \multicolumn{6}{|l|}{$n=59$} \\
\hline & Baseline & $\begin{array}{l}\text { Post- } \\
\text { test }\end{array}$ & $p^{\mathrm{a}}$ & Difference & Baseline & $\begin{array}{l}\text { Post- } \\
\text { test }\end{array}$ & $p^{\mathrm{a}}$ & Difference & $p^{\mathrm{b}}$ & $\begin{array}{l}\text { Effect } \\
\text { size }\end{array}$ \\
\hline \multirow{2}{*}{$\begin{array}{l}\text { SSCP, } \\
\text { median } \\
\text { (inter- } \\
\text { quartile } \\
\text { range) }\end{array}$} & 74.0 & 69.0 & $<0.001$ & -3.0 & 71.0 & 62.0 & $<0.001$ & -9.0 & $<0.001$ & 0.41 \\
\hline & $\begin{array}{l}(67.0- \\
82.0)\end{array}$ & $\begin{array}{l}(64.3- \\
77.8)\end{array}$ & & $\begin{array}{l}(-7.0- \\
1.0)\end{array}$ & $\begin{array}{l}(66.0- \\
80.0)\end{array}$ & $\begin{array}{l}(54.0- \\
67.0)\end{array}$ & & $\begin{array}{l}(-16.0- \\
-5.0)\end{array}$ & & \\
\hline \multirow{2}{*}{$\begin{array}{l}\text { Factor } \\
\text { I, } \\
\text { median } \\
\text { (inter- } \\
\text { quartile } \\
\text { range) }\end{array}$} & 32.0 & 29.5 & $<0.001$ & -1.0 & 31.0 & 25.0 & $<0.001$ & -4.0 & 0.001 & 0.32 \\
\hline & $\begin{array}{l}(29.0- \\
37.0)\end{array}$ & $\begin{array}{l}(26.0- \\
35.0)\end{array}$ & & $(-5.0-0)$ & $\begin{array}{l}(26.0- \\
36.0)\end{array}$ & $\begin{array}{l}(22.0- \\
30.0)\end{array}$ & & 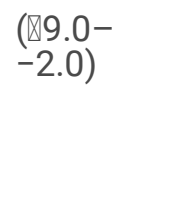 & & \\
\hline \multirow{2}{*}{$\begin{array}{l}\text { Factor } \\
\text { II, } \\
\text { median } \\
\text { (inter- } \\
\text { quartile } \\
\text { range) }\end{array}$} & 20.0 & 18.0 & 0.02 & -1.0 & 20.0 & 16.0 & $<0.001$ & -5.0 & $<0.001$ & 0.49 \\
\hline & $\begin{array}{l}(18.0- \\
22.0)\end{array}$ & $\begin{array}{l}(17.0- \\
21.8)\end{array}$ & & $\begin{array}{l}(-2.8- \\
1.0)\end{array}$ & $\begin{array}{l}(18.0- \\
22.0)\end{array}$ & $\begin{array}{l}(12.0- \\
18.0)\end{array}$ & & $\begin{array}{l}(-7.0- \\
-2.0)\end{array}$ & & \\
\hline \multirow{2}{*}{$\begin{array}{l}\text { Factor } \\
\text { III, } \\
\text { median } \\
\text { (inter- } \\
\text { quartile } \\
\text { range) }\end{array}$} & 12.0 & 11.0 & 0.01 & -1.0 & 11.0 & 10.0 & 0.04 & -1.0 & 0.94 & 0.01 \\
\hline & $\begin{array}{l}(9.0- \\
14.0)\end{array}$ & $\begin{array}{l}(9.0- \\
13.0)\end{array}$ & & $(-2.0-0)$ & $\begin{array}{l}(9.0- \\
13.0)\end{array}$ & $\begin{array}{l}(8.0- \\
12.0)\end{array}$ & & $\begin{array}{l}(-2.0- \\
1.0)\end{array}$ & & \\
\hline \multirow{2}{*}{$\begin{array}{l}\text { Factor } \\
\text { IV, } \\
\text { median } \\
\text { (inter- } \\
\text { quartile } \\
\text { range) }\end{array}$} & 10.0 & 10.0 & 0.52 & 0.0 & 10.0 & 9.0 & 0.35 & 0.0 & 0.18 & 0.13 \\
\hline & $\begin{array}{l}(9.0- \\
11.8)\end{array}$ & $\begin{array}{l}(9.0- \\
11.0)\end{array}$ & & $\begin{array}{l}(-1.0- \\
1.0)\end{array}$ & $\begin{array}{l}(8.0- \\
12.0)\end{array}$ & $\begin{array}{l}(8.0- \\
10.0)\end{array}$ & & $\begin{array}{l}(-1.0- \\
1.0)\end{array}$ & & \\
\hline
\end{tabular}

a. vs. each baseline

b: vs. Lecture group

Factor I: social distance at work

Factor II: recognition towards patients with schizophrenia

Factor III: self-disclosure

Factor IV: social distance in daily life

Table 4. Effects of demographic characteristics on differences in the stigma for changes in SSCP scores 


\begin{tabular}{|c|c|c|c|}
\hline \multirow[t]{2}{*}{ Characteristics } & \multirow{2}{*}{$\begin{array}{l}\text { Lecture group } \\
n=56\end{array}$} & \multicolumn{2}{|l|}{$\begin{array}{l}\text { Communication } \\
\text { group }\end{array}$} \\
\hline & & $n=59$ & $p$ \\
\hline Gender, Female & $-2.0(-7.0-1.0)$ & $-10.0(-21.0--7.0)$ & $<0.001$ \\
\hline Male & $-3.0(-8.0-1.0)$ & $-8.0(-14.5--4.0)$ & 0.008 \\
\hline Age, 20-29 & $-3.0(-7.0-0.0)$ & $-12.0(-21.0--7.0)$ & 0.006 \\
\hline $30-39$ & $-2.0(-6.5-2.0)$ & $-9.0(-21.0--3.0)$ & 0.007 \\
\hline $40-49$ & $-6.0(-12.0-1.5)$ & $-7.5(-9.3--4.0)$ & 0.616 \\
\hline $50<$ & $-3.0(-7.0--2.0)$ & $-13.0(-16.0--7.5)$ & 0.071 \\
\hline Has visited a mental hospital, positive & $-3.0(-4.5-2.5)$ & $-8.0(-15.5--4.5)$ & 0.007 \\
\hline negative & $-3.0(-8.0-1.0)$ & $-9.0(-17.0--5.0)$ & $<0.001$ \\
\hline $\begin{array}{l}\text { Experience of mental illness via a family member or close friend, } \\
\text { positive }\end{array}$ & $-1.5(-6.5-2.3)$ & $-9.0(-17.0--8.0)$ & 0.001 \\
\hline negative & $-3.0(-7.0-0.3)$ & $-8.5(-16.0--4.0)$ & 0.003 \\
\hline $\begin{array}{l}\text { Experience of schizophrenia via a family member or close friend, } \\
\text { positive }\end{array}$ & $1.0(-7.0-3.0)$ & $-8.0(-13.0--3.8)$ & 0.10 \\
\hline negative & $-3.0(-7.0-0.5)$ & $-9.0(-16.5--5.0)$ & $<0.001$ \\
\hline Psychiatric work experience, positive & $-2.0(-6.5-0.0)$ & $-9.0(-16.0--4.0)$ & 0.024 \\
\hline negative & $-3.0(-7.0-1.0)$ & $-9.0(-17.8--5.3)$ & $<0.001$ \\
\hline \multicolumn{4}{|l|}{ Frequency of medication counseling for schizophrenia patients } \\
\hline Almost every day & - & - & - \\
\hline A few patients a week & $-3.0(-4.0-2.0)$ & $-9.0(-18.0-2.0)$ & 0.26 \\
\hline A few patients a month & $-3.5(-7.8-1.0)$ & $-9.0(-12.0--4.0)$ & 0.014 \\
\hline A few patients a year & $\begin{array}{l}-2.5(-10.0- \\
-0.25)\end{array}$ & $-9.0(-21.0--5.0)$ & 0.035 \\
\hline Nothing & $-3.0(-6.0-5.0)$ & $-9.0(-35.0--7.0)$ & 0.017 \\
\hline
\end{tabular}

The values in the table represent changes in the median (inter-quartile range) total SSCP score

\section{Figures}




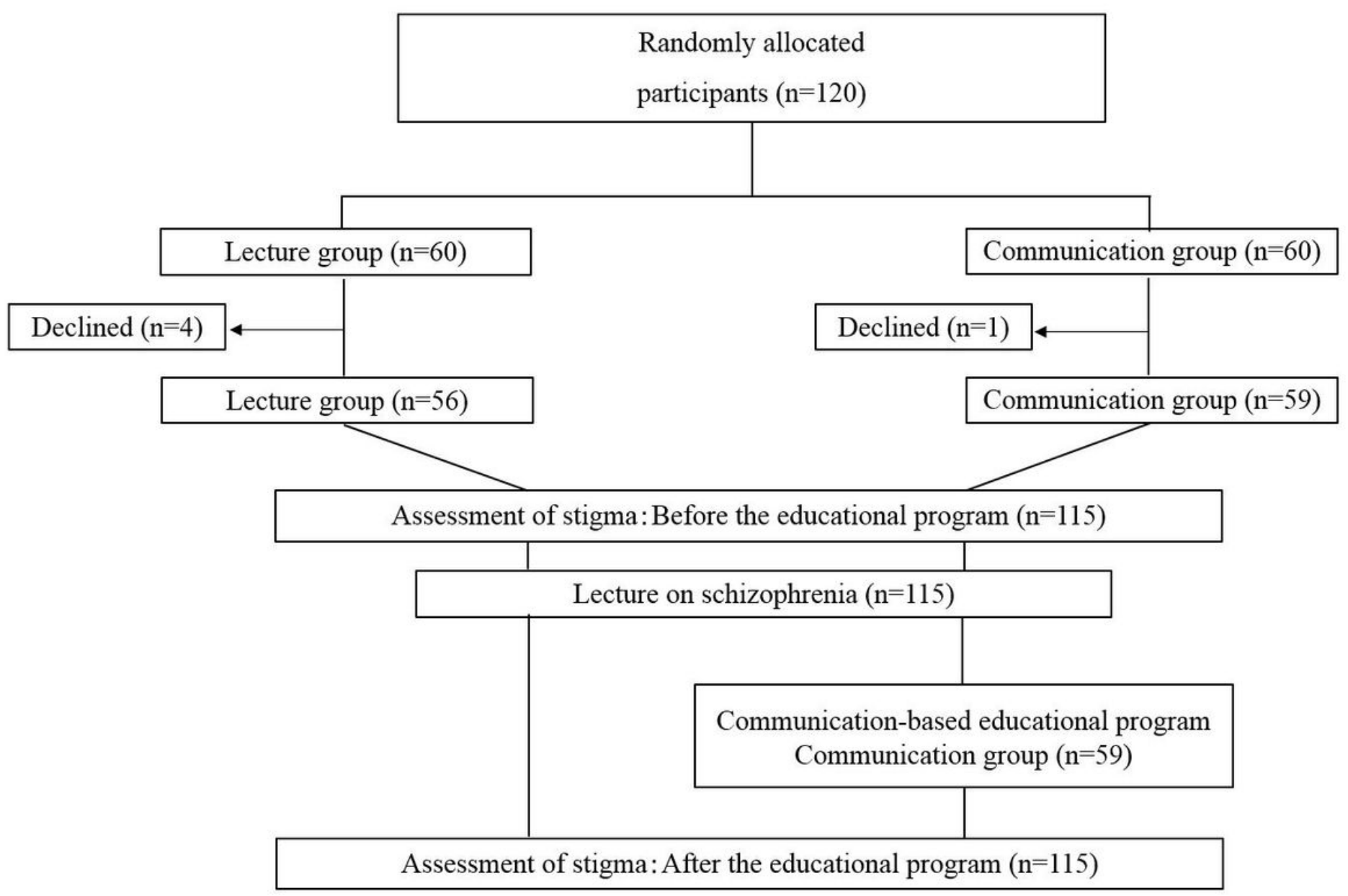

\section{Figure 1}

Study design 